\title{
Possibilities and limitation of prenatal diagnosis and carrier determination for Duchenne and Becker muscular dystrophy using cDNA probes
}

\begin{abstract}
A SPEER*, A W J SPIEGLER $\dagger$, R HANKE*, K GRADE*, U GIERTLER , J SCHIECK\&, S FORREST\|, K E DAVIES\|, R NEUMANN*, R BOLLMANNף, C BOMMER**, D SOMMER**, AND C COUTELLE*

From * the Central Institute of Molecular Biology, Department of Human Molecular Genetics, Academy of Science GDR, Berlin, GDR; †Department of Medical Genetics, and $¥$ Clinic for Paediatrics, Medical Academy Erfurt, Erfurt, GDR; \$Marienstift Arndtstadt, Arndtstadt, GDR; \|Nuffield Department of Clinical Medicine, John Radcliffe Hospital, Oxford; and \University Clinic for Obstetrics and Gynaecology, and **Department of Human Genetics, Charite Hospital, Humboldt University, Berlin, GDR.
\end{abstract}

SUMmARY Two cDNA probes, cf23a and cf56a, identify deletions of selected exons in about $50 \%$ of our DMD/BMD patients. We have estimated the most likely order of the 11 exons detectable with both probes with respect to the different extensions of the deletions. In one of our BMD pedigrees, the observed deletion could be traced in the affected males through three generations. This result shows that with the use of cDNA probes detecting deletions, the only risk of error in genomic prenatal diagnosis is the general high frequency of new mutations for DMD/BMD. This is important progress in diagnosis compared to the 2 to $5 \%$ risk of misdiagnosis because of crossing over events using conventional linkage analysis with bridging or intragenic probes. The first prenatal diagnosis of an unaffected fetus of a woman who is a DMD carrier according to ultrasound examination is described. In one of our DMD males, the cDNA probe cf56a detects a deletion breakpoint. His sister also shows the altered band and is therefore a DMD carrier, while his mother has a totally normal band pattern. The interpretation of this observation could be either germline mosaicism or two identical new mutations. The identification of deletion breakpoints is a new diagnostic strategy, especially for carrier determination, which excludes misdiagnosis owing to crossing over events and the problems of dosage estimation. It is, however, limited by the low frequency of breakpoints detectable with cDNA probes. Therefore, the generation of new intron probes in this region is an important goal.

Duchenne muscular dystrophy (DMD) and its clinically milder allelic form, Becker muscular dystrophy (BMD), are the most common $\mathrm{X}$ linked recessive genetic disorders affecting about one in $\mathbf{3 0 0 0}$ males. DNA diagnosis has resulted in dramatic progress in carrier detection and prenatal analysis for affected families. ${ }^{1-3}$ However, since up to now it has been predominantly based on linkage analyses, its reliability was limited by the possibility of crossing over events. This has caused difficulties in decision making for pregnant women, particularly in prenatal diagnosis.

Received for publication 6 January 1988.

Revised version accepted for publication 26 April 1988.

\section{Material and methods}

MOLECULAR PROBES

The cDNA probes used were $\mathrm{Cf} 23 \mathrm{a}^{4}{ }^{5}$ and Cf56a.

MOLECULAR ANALYSIS

DNA preparation, restriction enzyme digests, and electrophoresis were performed as described previously. ${ }^{1}$ As transfer matrix we used either Hybond N TM ${ }^{1}$ or CCA paper. ${ }^{6}$ The labelling of the DNA probes was carried out by nick translation or hexanucleotide primed labelling. Creatine kinase was determined with the $\mathrm{N}$-acetyl-cystein (NAC) activated creatine kinase (monotest Boehringer 126.322). Normal values have been determined for 
different age groups. ${ }^{7}$ Ultrasound carrier determinations were performed according to van Rohden and Steinbicker. ${ }^{8}$

\section{Results}

We searched for deletions in affected males from 13
BMD families with the cDNA probes cf $23 a$ and cf56a. In four of these families a deletion wa detectable with cf23a. Twenty-one DMD males out of a total of 45 showed a deletion with the $\mathrm{cDN}$. probes cf23a and cf56a (13/cf23a, 14/cf56a, 6/cf23 and cf56a). Different hybridisation patterns of thes $\bar{\oplus}$ deletion patients are shown in fig 1 . Fig 2 sum
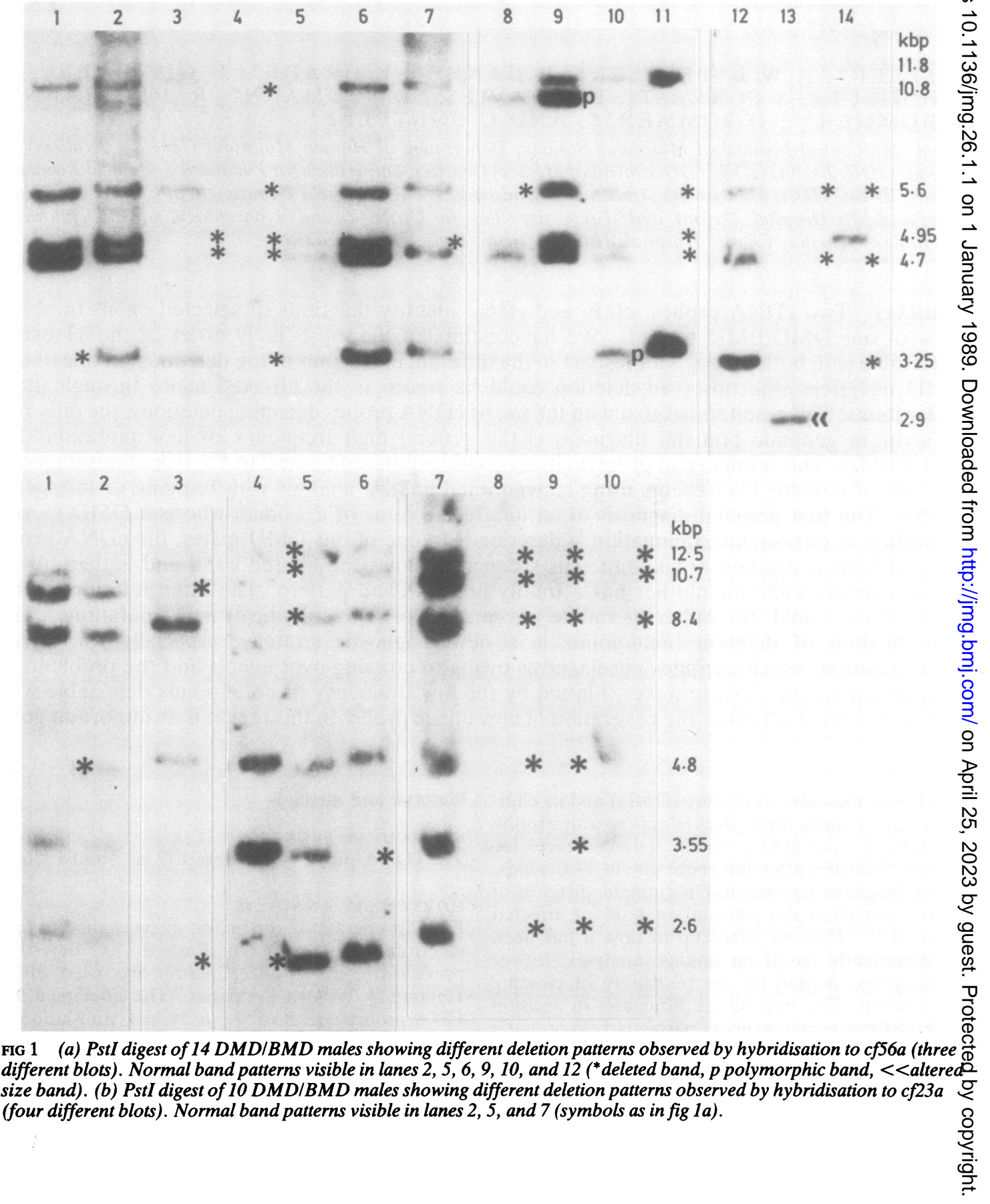
marises schematically 18 of the 25 described deletions and the most likely order of the exons. Five deletions extend to the whole region and two are different from the given exon order.

Fig 3 shows the pedigree of a BMD family, in which BMD males of the third, fourth, and fifth generation are alive. This allows us to follow the exon deletions found in this family over three generations. The observed deletion of the $3.55 \mathrm{kbp}$ exon detectable with $\mathrm{cf} 23 \mathrm{a}$ in a Pst $\mathrm{J}$ digest and the $4.95 \mathrm{kbp}$ and $4.7 \mathrm{kbp}$ exon detectable with cf56a in a
Pst I digest (data not shown) were inherited by every BMD male but not by the unaffected ones. This shows the conserved inheritance over many generations of such exon deletions.

The results of our first prenatal diagnosis in a DMD family using a deletion of all five exons detectable in a PstI digest with cf56a is shown in fig 4. The cytogenetically identified male fetus (lane 2) of a DMD carrier identified by ultrasound examination (III.7) shows, in contrast to one of the affected boys of the family (lane 3), the same hybridisation

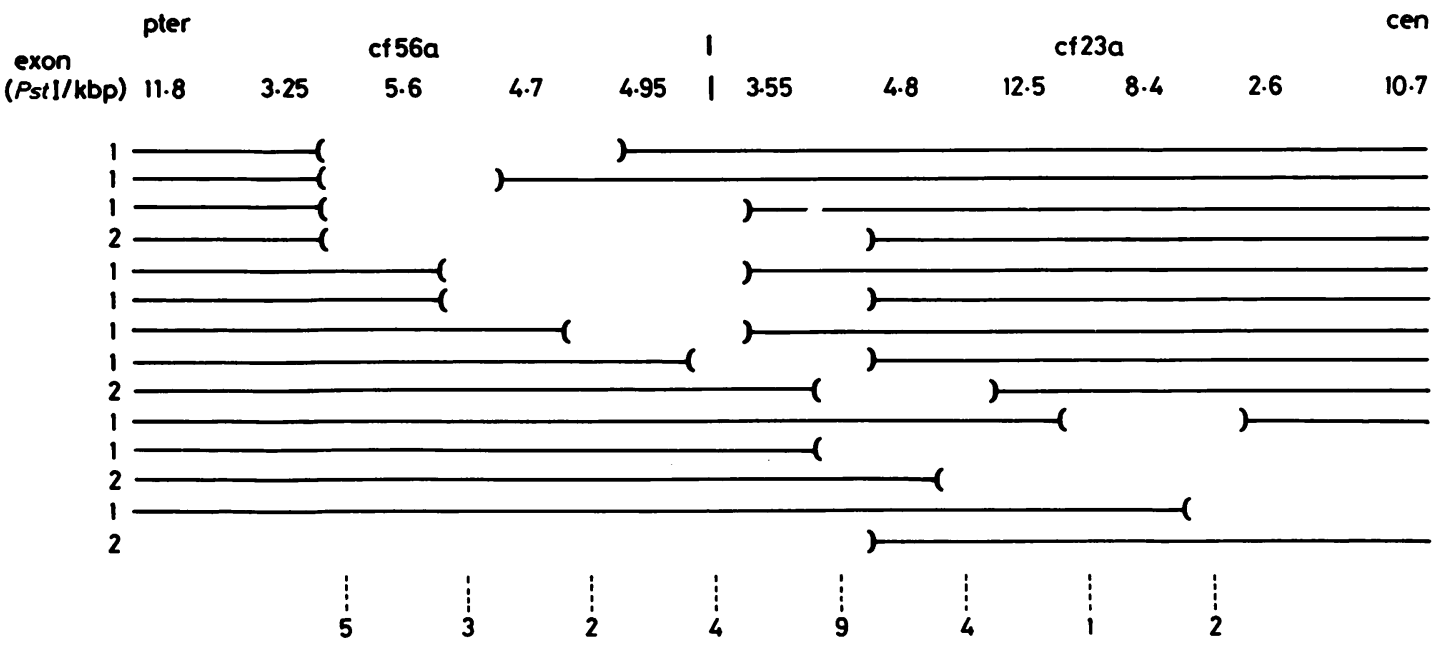

FIG 2 Compilation of 18 deletion cases. The figures to the left give the numbers of identical exon deletions.

The top numbers show the most likely order of the detectable bands (exons) after PstI digestion and hybridisation to cf56a and cf23a respectively, as deduced from the deletions of our patients. The total number of breakpoints within the same intron region is given at the bottom.

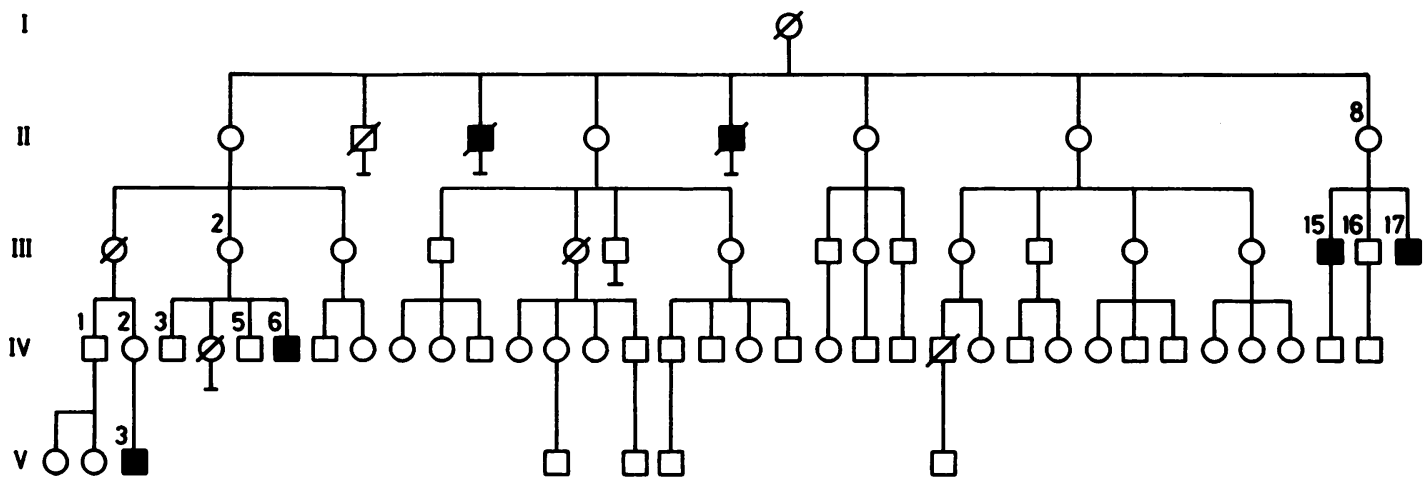

FIG 3 Pedigree of a BMD family. 

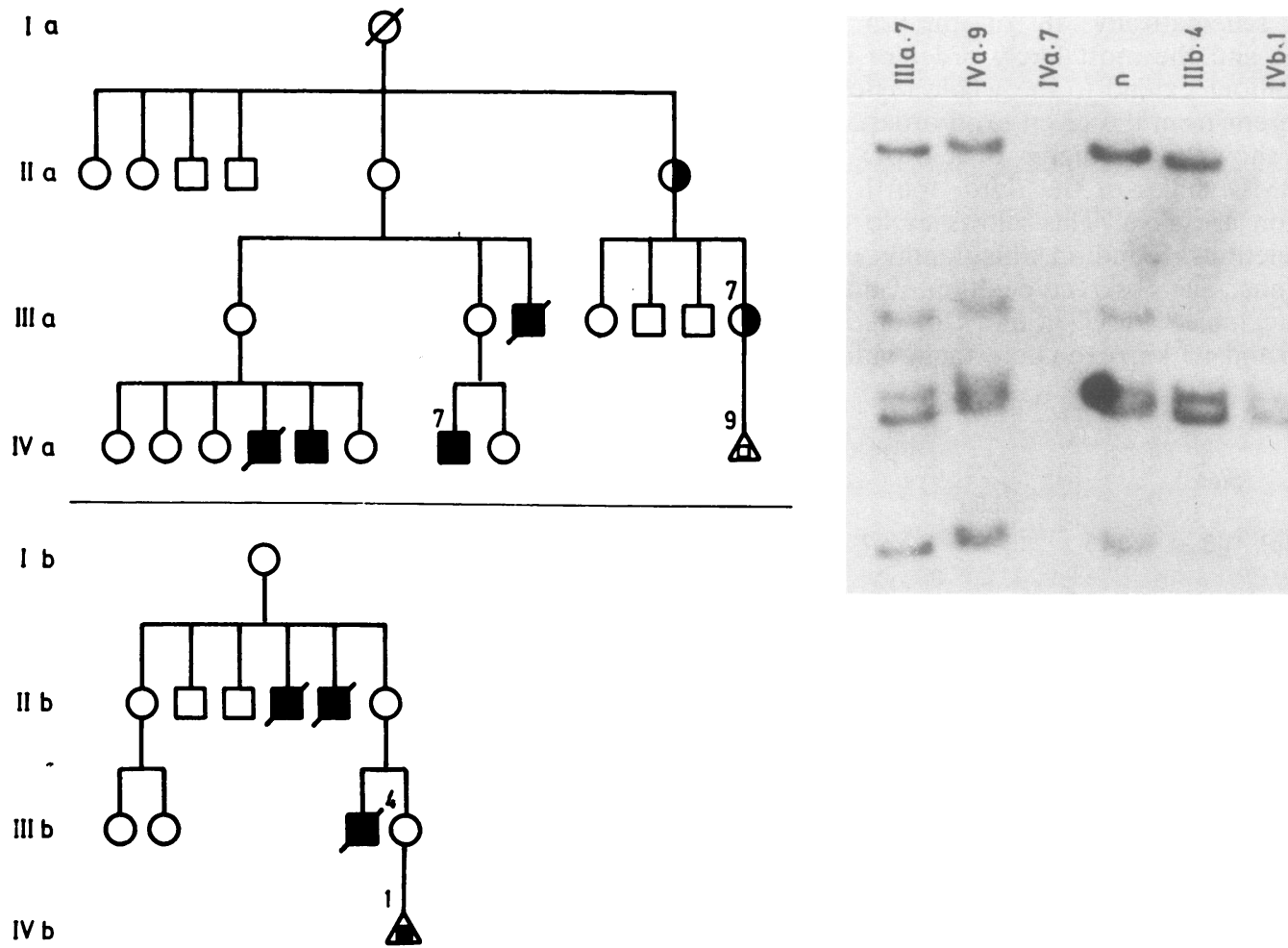

FIG 4 Pedigree of two DMD families and PstI digests of family members who are relevant for prenatal diagnosis hybridised $\overrightarrow{\vec{P}}$ to cf56a. (O DMD carrier according to ultrasound examination, $\triangle$ fetus with DMD, $\triangle$ fetus without DMD, $n$ normal male control.)

pattern as the normal male control (lane 4). We therefore diagnosed an unaffected boy. The pregnancy is still in progress.

Lanes 5 and 6 in fig 4 show DNA analysis with the probe cf56a of a woman and the aborted material of her male fetus. This woman (III.4) was identified as a DMD carrier by DNA analysis with the probe 754 . Prenatal diagnosis based on a deletion with cDNA probes was not possible because no DMD male is alive in this family. The woman, who was not prepared to accept an error of 2 to $10 \%$ in the prenatal diagnosis, requested termination of pregnancy after the cytogenetic determination of a male fetus. The DNA hybridisation pattern of the fetal material in a PstI digest with cf56a shows a deletion of three exons. Therefore, we concluded that the fetus was affected. This result can be used as a reference for the DNA analysis of further male pregnancies of this woman.

In one case (lane 13, fig 1a) one deletion breakpoint was detectable with cf56a by the appearance of an altered $2.9 \mathrm{kbp}$ band instead of the
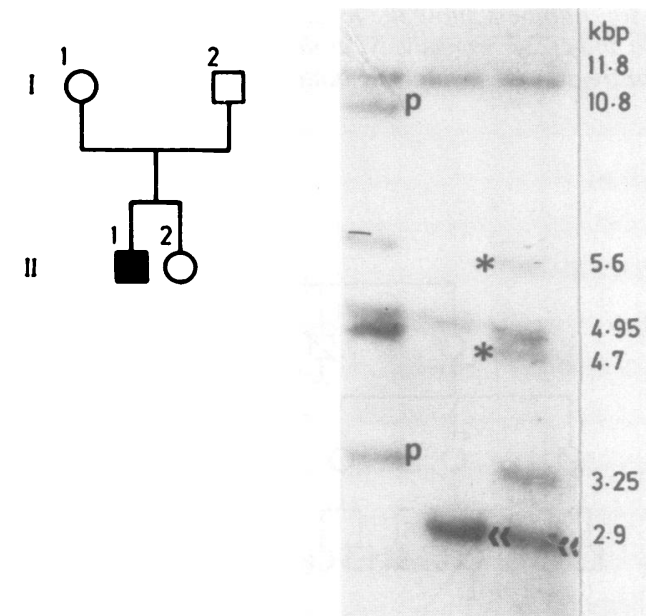

FIG 5 Pedigree of a DMD family and PstI digest of family members who are relevant for carrier determination using an altered band. Hybridisation is to cf56a. (Symbols as in figs la and 3.) 
normal $3.25 \mathrm{kbp}$ one. We used this observation for carrier determination in the affected family (fig 5). The sister (II.2) of the DMD male (II-1) has also inherited the altered band and is therefore a DMD carrier, while the mother $(\mathrm{I} \cdot 1)$ shows a normal band pattern with the two polymorphic alleles, $10.8 \mathrm{kbp}$ and $3.25 \mathrm{kbp}$. This could be interpreted as germline mosaicism or the occurrence of two identical new mutations.

\section{Discussion}

The discovery of deletions detectable with DMD gene probes in about $10 \%$ of DMD males $^{910}$ resulted in new possibilities for prenatal diagnosis, excluding the risk of misdiagnosis owing to crossing over events. However, this new diagnostic strategy in prenatal diagnosis of DMD/BMD has so far been limited by the relatively small number of deletions detectable with these probes. The isolation of cDNA clones from the DMD/BMD gene region ${ }^{4}{ }^{11-13}$ has changed the situation dramatically, because deletions have been detected in about $50 \%$ of all DMD/BMD cases by application of such exon probes. This makes this strategy applicable on a much broader scale, including the investigation of fetal tissue after termination of male pregnancies in families in which no living DMD/BMD male is available for reference.

Obviously the main field for deletion analysis is in prenatal diagnosis, while carrier determination suffers from the problems of dosage analysis with a risk of misdiagnosis of about $5 \%$, comparable to that of linkage analysis. This limitation could be overcome by identifying deletion breakpoints, detectable by a size change of hybridisation bands, but in general such breakpoints are so far away from the exons that cDNA probes can detect them only in a few cases. Therefore, the isolation of specific intron probes is necessary for a broader application of breakpoint detection in carrier determination of DMD/BMD.

We are grateful to many clinical colleagues, particularly Drs Gerhardt, Grieger, Herrmann, Kunath, Kaufmann, Krebs, Metzke, Steinbicker, Szibor, Thiel, and Wulff. This work was supported by the Ministry of Health of the GDR. AS was funded by a Wellcome Trust Travelling Fellowship. KED and SF are grateful to the Medical Research Council, Muscular Dystrophy Group of Great Britain, and the Muscular Dystrophy Association, USA for financial support.

\section{References}

1 Speer A, Davies KE, McGlade S, et al. Biomed Biochim Acta 1986;45:K19-K27.

2 Old JM, Davies KE. Prenatal diagnosis of Duchenne muscular dystrophy by DNA analysis. J Med Genet 1986;23:556-9.

${ }^{3}$ Hodgson S, Walker A, Cole C, et al. The application of linkage analysis to genetic counselling in families with Duchenne or Becker muscular dystrophy. J Med Genet 1987;24:152-9.

4 Cross GS, Speer A, Rosenthal A, et al. Deletions of a muscle cDNA in Duchenne and Becker muscular dystrophy patients. EMBO J 1987;6:3277-83.

5 Forrest SM, Cross GS, Speer A, Gardner-Medwin D, Burn J, Davies KE. Preferential deletion of exons in Duchenne and Becker muscular dystrophies. Nature 1987;329:638-40.

6 Hunger HD, Speer A, Flachmeier C, Hanke R, Behrendt G, Coutelle $C$. Use of cyanuric chloride-activated paper for detection of subpicogram quantities of specific DNA sequences and its application to linked restriction fragment length polymorphism analysis in a Duchenne muscular dystrophy affected family. Anal Biochem 1987;165:38-45.

7 Spiegler AWJ, Wiedeman G, Herrmann FH, et al. Altersabhangigkeit der creatinkinase-(CK) Aktivitat im Serum: Referenzwerte zur Konduktorinnendiagnostik bei DuchenneMuskeldythropie (DMD). Dtsch Gesundheitswes 1982;37:2209 13.

${ }^{8}$ Van Rohden L, Steinbicker V. Ultraschalltomographie-ein Verfahren zur Differentialdiagnostik neuromuskularer Erkrankungen. Psychiatr Neurol Med Psychol (Leipz) (in press).

9 Kunkel LM, Hejtmancik JF, Caskey CT, et al. Analysis of deletions in DNA from patients with Becker and Duchenne muscular dystrophy. Nature 1986;322:73-7.

10 Smith TJ, Wilson L, Kenwrick SJ, et al. Isolation of a conserved sequence deleted in Duchenne muscular dystrophy patients. Nucleic Acids Res 1987;15:2167-74.

1 Monaco AP, Neve RL, Colletti-Feener C, Kurnit DM, Kunkel LM. Isolation of candidate cDNAs for portions of Duchenne muscular dystrophy gene. Nature 1986;32:646-50.

12 Koenig M, Hoffman EP, Bertelson CJ, Monaco AP, Feener C, Kunkel LM. Complete cloning of the Duchenne muscular dystrophy (DMD) cDNA and preliminary genomic organisation of the DMD gene in normal and affected individuals. Cell 1987;50:509-17.

13 Burghes AHM, Logan C, Hu X, Belfall B, Worton R, Ray PN. Isolation of a cDNA clone from the region of an $X ; 21$ translocation that breaks within the Duchenne/Becker muscular dystrophy gene. Nature 1987;328:434-7.

Correspondence and requests for reprints to Dr A Speer, Central Institute of Molecular Biology, Department of Human Genetics, Academy of Science GDR, Berlin, GDR. 